$1 \quad$ Laura Sandberger-Loua $^{1}$, Heike Feldhaar ${ }^{2}$, Robert Jehle $^{3} \&$ Mark-Oliver Rödel $^{1}$

2

\title{
3 Multiple paternity in a viviparous toad with internal fertilisation
}

4

$5 \quad{ }^{1}$ Museum für Naturkunde Leibniz Institute for Evolution and Biodiversity Science

6 Invalidenstraße43

$7 \quad 10115$ Berlin

8 Germany

9 Corresponding author: Laura Sandberger-Loua, laura.sandberger@mfn-berlin.de, phone: 049

$10 \quad 3020939098$

11 Mark-Oliver Rödel, mo.roedel@mfn-berlin.de

12

$13{ }^{2}$ Animal Ecology I, Bayreuth Centre for Ecology and Environmental Research (BayCEER)

14 University of Bayreuth

15 Universitätsstr. 30

1695540 Bayreuth

17 Germany

18 Heike Feldhaar, Feldhaar@uni-bayreuth.de

19

$20{ }^{3}$ School of Environment \& Life Sciences, University of Salford

$21 \quad$ M5 4WT Salford

22 United Kingdom

23 Robert Jehle, r.jehle@salford.ac.uk 


\section{Abstract}

26 Anurans are renowned for a high diversity of reproductive modes, but less than $1 \%$ of species

27 exhibit internal fertilisation followed by viviparity. In the live bearing West African Nimba

28 toad (Nimbaphrynoides occidentalis), females produce yolk-poor eggs and internally nourish their young after fertilisation. Birth of fully developed juveniles takes place after nine months. In the present study, we used genetic markers (eight microsatellite loci) to assign the paternity of litters of 12 females comprising on average 9.7 juveniles. In nine out of twelve families (75\%) a single sire was sufficient; in three families $(25 \%)$ more than one sire was necessary to explain the observed genotypes in each family. These findings are backed up with field observations of male resource defence (underground cavities in which mating takes place) as well as coercive mating attempts, suggesting that the observed moderate level of multiple paternity in a species without distinct sperm storage organs is governed by a balance of female mate choice and male reproductive strategies.

Keywords: multiple paternity, internal fertilisation, operational sex ratio, male harassment, Amphibia, Nimbaphrynoides occidentalis

\section{Introduction}

It is now well established that polyandry is more common in the animal kingdom than originally assumed (Pizzari and Wedell, 2013). For females, advantages of multiple matings include an increased availability of ressources provided by males (Gray, 1997), enhanced fertilisation success (Caspers et al., 2014; Plough et al., 2014), higher genetic heterogeneity

47 (Nichols et al., 2015; Rovelli et al., 2015) and genetic quality of offspring (Bouwman et al., 2006; Byrne and Whiting, 2011; Johnson and Brockmann, 2013). In species with internal fertilisation, polyandry also enables females to excert cryptic choice of fertilising males (for 
reviews see Parker and Birkhead, 2013; Simmons, 2005). Negative effects of polyandry for females can include higher predation risk (Arnqvist, 1989) and female injuries during mating (Xavier, 1971), and a higher probability to suffer from sexually transmitted parasites and diseases (Ashby and Gupta, 2013). Males, on the other hand, generally maximise their reproductive success through rather opportunistic and sometimes coercive matings (Arnqvist, 1989; Arnqvist and Kirkpatrick, 2005; Sztatecsny et al., 2006). However, male mating strategies that involve for example territoriality can also reduce the level of polyandry through female monopolisation (e.g.: Arnqvist and Kirkpatrick, 2005). Apart from differential mating strategies exhibited by each sex, levels of polyandry are also governed by reproductive life histories. Among the classes of vertebrates, amphibians arguably demonstrate the highest diversity of reproductive modes (Duellman and Trueb, 1986; Wells, 2010). Caecilians and caudates are generally characterised by internal fertilisation (Wake, 1993), with sperm storage organs allowing for sperm competition and multiple paternity which are possibly influenced by cryptic female choice (Caspers et al., 2014; Jehle et al., 2007; Kupfer et al., 2008; Rovelli et al., 2015). In anurans, on the other hand, the vast majority of species fertilise their eggs externally (Wake, 1993, 2015a). Polyandry in anurans is common (for a review see Byrne and Roberts, 2012) and male mating tactics such as multiple amplexi (Byrne and Roberts, 1999; Byrne and Whiting, 2011), clutch piracy (Vieites et al., 2004) and possibly the release of stray sperm into aquatic environments

69 (Hase and Shimada, 2014) can lead to multiple paternity within single clutches beyond the 70 control of females. Internal fertilisation is a prerequisite for viviparity through uterine egg retention until an advanced developmental stage (Wake, 1993, 2015a, 2015b). However, while viviparity is common in caecilians, it is only exhibited by $2.7 \%$ of caudates (Buckley, 2012; Wake, 2015a, 2015b). In anurans, only $0.3 \%$ of species (17 out of approximately 6600, Frost, 2015) from 
five genera are known or assumed to be viviparous, comprising three different viviparous reproductive modes (Haddad and Prado, 2005; Iskandar et al., 2014). One mode is generally termed ovo-viviparous, in which yolk-rich eggs are retained in the uterus and juveniles are born after metamorphosis (Haddad and Prado, 2005; Lamotte and Xavier, 1972; Wake, 1978). This is the viviparous reproductive mode known or assumed for 15 viviparous anuran species, whereas the remaining two modes are each known from only a single anuran species. The second viviparous reproductive mode is generally termed viviparous, or truly viviparous, in which mothers nourish their larvae during gestation and juveniles are born after metamorphosis (Haddad and Prado, 2005; Xavier, 1977, 1986). Only recently the third viviparous reproductive mode was discovered: Limnonectes larvaepartus giving birth to tadpoles (Iskandar et al., 2014). In comparison to oviparous species, viviparity is often more costly for females, as clutch sizes are restricted by the available intra-uterine space and locomotion may be reduced (Blackburn, 1999; Shine, 1987; Wourms and Lombardi, 1992). Compared to egg-laying internal fertilisers, cryptic female choice should therefore pose a particular advantage to viviparous species.

The West African Nimba toad (Nimbaphrynoides occidentalis) is the only known anuran representative of the truly viviparous reproductive mode (Wake, 2015b; Wells, 2010; Xavier, 1986). Nimba toads mate at the end of the rainy season (September-November), before moving underground until the beginning of the next rainy season in March or April (Lamotte, 1959). After internal fertilisation of small, yolk-poor eggs ( $500 \mu \mathrm{m}$ in diameter, Xavier, 1986), females nourish their foetuses (matrotrophy) and give birth to 4-17 fully developed juveniles (pueriparity) after about 9 months (Lamotte, 1959). At a longevity of 3-5 years (Castanet et al., 2000), lifetime reproductive output per female is low. In the present paper we focus on the Nimba toad to, for the first time, elucidate patterns of paternity in a viviparous anuran with internal fertilisation. More specifically, we link our 
100 findings from genetic parentage analyses of litters derived from known females with

101 behavioural field observations of male fighting and mating attempts. Together with

102 presenting data on operational sex ratios, we discuss whether internal fertilisation in the

103 Nimba toad leads to a genetic mating system which can be more controlled by females

104 compared to the external fertilisation which is exhibited by the vast majority of anurans.

105

106 Materials and Methods

$107 \quad$ Field work

108 The study was conducted in the high altitude grasslands of the Guinean Nimba Mountains,

109 West Africa. The area is characterised by a dry season from December to March and a rainy

110 season from April to November, a seasonality which has a strong influence on Nimba toad

111 abundance and sex ratios (Lamotte, 1959). A male-biased operational sex ratio (OSR) was

112 previously hypothesised to be the main driver for anuran polyandry (Byrne and Roberts,

113 2012; Hase and Shimada, 2014; Lodé et al., 2005; Sztatecsny et al., 2006). Therefore, we

114 estimated the average OSR per calendar week within the rainy season based on annual

115 monitoring data from 2007 to 2014 . We included 333 areas of 5 x $5 \mathrm{~m}$ in size at a search

116 effort of 90 person minutes (for more details see Hillers et al., 2008; Sandberger-Loua et al.,

117 2016). Weekly OSRs were fitted to an additive generalised model using the mgcv package in

118 R (Wood, 2011).

119 We collected 12 gestating females in the field, and kept them singly in plastic terraria about 5

$120 \mathrm{~km}$ from the capture location, feeding them with small flying insects and termites. Humidity

121 levels were kept high through moistened polyurethane foam, and the temperature was kept at

122 levels representing their natural environment $\left(20-25^{\circ} \mathrm{C}\right)$. All females gave birth between three

123 and 10 days after capture. After birth, we clipped a tip of the second toe from the mother and

124 all offspring (following procedures described in (Grafe et al., 2011)), to store in 98\% ethanol 
125 for DNA analysis. All toads (mothers and juveniles) appeared in good condition after this

126 procedure and were released where the mother had been caught.

Development of microsatellite loci for N. occidentalis

129 We used up to eight newly developed microsatellite loci to determine the number of fathers

130 in each litter. For development of a genomic library, DNA was extracted from thigh muscles

131 of six individuals using Puregene DNA Purification Kit (Gentra Systems) according to the

132 manufacturer's recommendations. GENterprise Genomics (Mainz, Germany;

$133 \mathrm{http}: / /$ genterprise.de) was contracted to develop a repeat-enriched library. Twenty-seven

134 sequences containing more than eight repeats and sufficient flanking regions were chosen to

135 design PCR primers using Primer3 (Rozen and Skaletsky, 2000). Eight loci proved

136 polymorphic and unambiguously scorable based on an initial test with 4 individuals and

137 subsequent characterisation based in a further 40 individuals. Microsatellite sequences were

138 deposited in Genbank.

\section{Genotyping}

141 DNA for the paternity analysis was extracted using the Roche PCR template preparation kit

142 according to the manufacturer's recommendations. PCRs were performed using a $12.5 \mu 1$

143 PCR reaction volume containing $1 \times$ PCR-buffer, $2 \mathrm{mM} \mathrm{MgCl} 2,160 \mu \mathrm{M}$ dNTPs, $2.5 \mu \mathrm{M}$ of

144 each primer (forward primer labelled with fluorescent IR-700 or IR-800 dye by Licor), $0.5 \mathrm{U}$

145 of Taq DNA polymerase (New England BioLabs) and $1 \mu$ l of 1:10 diluted template DNA. All

146 loci were amplified on a 2720 Thermal Cycler (Applied Biosystems, version 2.09). Loci G07

147 and D03 were amplified using a fixed annealing temperature of $57^{\circ} \mathrm{C}$, and a touchdown

148 program was applied to all other loci (Nocc4, A09, C05, C10, E06 and F03). PCR conditions

149 for the two protocols were as follows: $57^{\circ} \mathrm{C}: 3 \mathrm{~min}$ at $94^{\circ} \mathrm{C}, 35$ cycles with $30 \mathrm{sec}$. each at 
$15094^{\circ} \mathrm{C}, 57^{\circ} \mathrm{C}$ and $72^{\circ} \mathrm{C}$, followed by $20 \mathrm{~min}$ at $72^{\circ} \mathrm{C}$; touchdown: $5 \mathrm{~min}$ at $94^{\circ} \mathrm{C}, 10$ cycles

151 with annealing temperature decreasing $0.5^{\circ} \mathrm{C}$ per cycle from $63^{\circ}-57^{\circ} \mathrm{C}$, with $30 \mathrm{sec}$. each at

$15294^{\circ} \mathrm{C}$, annealing temperature and at $72^{\circ} \mathrm{C}$, followed by 25 cycles with 30 sec. each at $94^{\circ} \mathrm{C}$,

$15355^{\circ} \mathrm{C}$ and $72^{\circ} \mathrm{C}$, followed by 7 min elongation at $72^{\circ} \mathrm{C}$. Allele lengths were analysed with

$154 \mathrm{SAGA}^{\mathrm{GT}}$ (LICOR). Primer characteristics are given in Table 1. To minimise scoring errors,

155 every sample was amplified at least twice for each locus.

Paternity analyses

158 We used two complementary approaches to estimate the minimum (GERUD) and the most

159 likely (COLONY) number of sires in each litter, respectively. In a first step, we applied the

160 maximum likelihood approach implemented in COLONY2 (Jones and Wang, 2010)

161 assuming a large error rate (10\%) to identify potential genotyping errors. The following

162 specifications were used: the maternal genotype was known, no candidate fathers included,

163 we gave no known population allele frequency, we used a sib-ship size prior and two runs of

164 medium length. Individuals whose alleles were classified as typing errors $(0.4 \%$ of alleles or

165 one allele in $3.4 \%$ of individuals) were genotyped a third time and in all cases the allele sizes

166 were confirmed. Final results from COLONY2 runs were subsequently derived with an

167 assumed error rate of zero (all other specifications as described above), and repeated a second

168 time with the inclusion of population-wide allele frequencies. Population-wide allele

169 frequencies were derived from a dataset from 600 adult toads (Sandberger-Loua et al.,

170 unpublished). As a second approach, we applied GERUD2.0 (Jones, 2005) to estimate the

171 minimum number of fathers to explain the observed genotypes. Because GERUD2.0 does not

172 allow for missing data, we had to alternatively exclude $17 \%$ of individuals or reduce the

173 number of markers used. The statistical power was assessed by running GERUD2.0sim

174 (Jones, 2005) 10 times with 1000 iterations, assuming that the mother's genotype is known, 
175 that one of 10 offspring is sired by a second male, and that either four or five loci are

176

177

178

180

181

182

183

184

185

186

187

188

189

190

191

192

193

194

195

196

197

198

available, based on the population wide allele frequencies. In all 10 runs, an additional father was recognised in $>99 \%$ of iterations, demonstrating that only a subset of available loci is sufficient for reliable paternity detection. We considered litters to contain multiple paternity when GERUD and COLONY independently identified multiple fathers, and when the number of most probable sires determined by COLONY was identical or larger than the minimum number of fathers estimated by GERUD. The effective mating frequency $\left(m_{e}\right)$, a quantity which takes the actual paternity of contributing males into account, was calculated as $m_{e}=\left(1 / \Sigma p i^{2}\right)$, where $p i$ is the proportion of offspring in a clutch sired by male $i$ (Starr, 1984).

\section{Results}

The 12 Nimba toad females gave birth to an average of 9.7 young each (range: 4-16; total 116). We genotyped 5-7 loci for each individual and included 117 individuals in the paternity analysis (12 mothers and 105 offspring, 11 young had to be discarded due to poor DNA quality, Table 2). The microsatellite markers proved highly polymorphic, comprising on average 14 alleles per locus (range: 7-19 alleles). All offspring could be unambiguously assigned to their mothers, and in nine out of twelve families a single sire was sufficient to explain the observed genotypes in each family. Three families contained multiple paternity as identified by both GERUD and COLONY, with the most successful male siring between 55$70 \%$ of offspring (effective mating frequency, $m_{\mathrm{e}}: 1.72-1.98$; Table 2 ). The same results were obtained when considering population allele frequencies (data not shown). However, whereas GERUD identified two fathers in all three cases, COLONY identified two families with two fathers and one family with three fathers. This discrepancy in sire number is due to GERUD and COLONY identifying the minimum and the most likely number of fathers, respectively. 
199 In total, $7.6 \%$ (COLONY) and 8.6\% (GERUD) of juveniles were estimated to be fathered by

200 a secondary sire.

201 The operational sex ratio (OSR) significantly progressed from a female bias at the beginning 202 of the mating season, increasing to a male bias towards the end of the mating season (GAM:

203 estimate: $0.55, t=10.17, p<0.001$, adjusted $r^{2}: 0.59$, Fig1).

Discussion

This is the first study examining genetic paternity in an anuran with internal fertilisation,

207 demonstrating the occurrence of multiple sires at a moderate proportion of examined litters.

208 In line with a high diversity of reproductive modes, previous studies on frequencies of multiple paternity in externally fertilising anurans revealed a range spanning from $0 \%$ (Brown et al., 2010) to over 90\% (Byrne and Whiting, 2011). For internally fertilising

211 caudates, multiple paternity was reported to range between 38\% (Caspers et al., 2014) and

$21296 \%$ of clutches (Adams et al., 2005). Our results for the Nimba toad (25\%) are lower than

213 those reported for caudates, and in the lower part of the anuran range. Polyandry allows for

214 fertility assurance, sperm competition, and possibly cryptic female choice (Birkhead, 1998).

215 In Nimba toads fertilisation rates have previously shown to be high (on average 90\%,

216 Lamotte et al., 1964). It is currently unknown whether in Nimba toads mating with high

217 quality males results in more eggs being ovulated (as observed e.g. in carnivore mammals,

218 Larivière and Ferguson, 2003). In contrast to other bufonids, Nimba toads engage in a lumbal 219 amplexus through which males clasp females in the region of their ovaries (Xavier, 1971), 220 possibly inducing or facilitating ovulation. However, females kept without males ovulate and 221 develop a pseudo-gestation (Xavier, 1974), and atresia of follicles should occur if not all 222 mature eggs are ovulated due to missing induction, but is very rare (Xavier, 1971; Xavier et 
al., 1970). Taken together, it seems likely that other factors than increased fertilisation success are the main drivers for polyandry.

In contrast to caudates, internally fertilising anurans have no apparent sperm storage organs (Wake, 2015a). In Nimba toads due to the development of a pseudo-gestation without mating as well in older females (> 2 years, Xavier, 1974), inter-season sperm storage can be excluded. Nevertheless, short-term sperm storage (hours to days) can still allow for sperm competition and cryptic female choice (Orr and Brennan, 2015). Relative testes size is generally correlated with the level of sperm competition (e.g. Dziminski et al., 2010). Accounting for about $0.4 \%$ of body weight, (Gavaud, 1976; own data), Nimba toad males have normal sized testes comparable to other anurans without evidence for elevated sperm competition (Kusano et al., 1991). Additionally, despite a large sample size of investigated females, no accumulation of sperm was found in their reproductive organs (Xavier 1971). Considering that amplexus in Nimba toads can last for more than one day (Xavier, 1971), cryptic female choice is only possible if spermatozoa remain viable for longer time periods than mating duration. Another possibility for females to favour offspring from high quality males, is to vary resource allocation. Gestating Nimba toad females secrete mucoproteins from uterine epithelial cells into the uterus cavity, on which developing young are orally feeding (Vilter and Lugand, 1959; Xavier, 1971, 1977). It is therefore likely difficult for

241 females to favour offspring sired by particular males. Hence, so far no indication for

242 increased sperm competition was recorded for males, nor sound indication for sperm

243 longevity or sperm storage in females, nor mechanisms enabling females to vary the provided 244 resources. Additionally, the prolonged amplexus is costly for females, as they are injured by 245 the tight grip and the nuptial spines of males (Xavier, 1971). Taken together, these

246 observations indicate that pre-mating female choice might be more important than post247 mating (cryptic) female choice in conjunction with sperm competition. 
248 In externally fertilising anurans, male display territories or defence of resources such as

249 breeding sites can facilitate female choice (Chen et al., 2011; Hudson and Fu, 2013; Lodé and

250 Lesbarrères, 2004). Our field observations suggest similar phenomena in Nimba toads. Males

251 defend entrances to underground cavities in which Nimba toads reside during the dry season

252 and in which matings are assumed to take place (Angel and Lamotte, 1947, see Online

253 Resource 1 for a field observation). To enter these cavities at the end of the rainy season,

254 females have to pass the guarding males, providing them an opportunity for mating.

255 Individual males can be observed over several weeks around the same cavity entrances which 256 they defend against other males (Sandberger-Loua, personal observation). Males also engage

257 in antagonistic behaviour accompanied by calling and often physical combat (see Online

258 Resource 2). Unfortunately, we were not able to sample DNA in the field from males to test

259 the hypothesis that individuals winning combats at entrances to dormancy cavities sire the

260 majority of offspring in given litters. Nevertheless, for externally fertilising anurans, within-

261 clutch multiple paternity appears to be lower for territorial species (0-29\%: Brown et al.,

262 2010; Chen et al., 2011; Hudson and Fu, 2013; Knopp and Merilä, 2009) compared to non-

263 territorial species (30 - > 90\%: Byrne and Roberts, 1999; Byrne and Whiting, 2011; Hase and

264 Shimada, 2014; Sztatecsny et al., 2006; Vieites et al., 2004). Despite reporting on an internal

265 fertiliser, our results are in line with the proportions of polyandry reported for other anurans

266 with territorial males, suggesting that Nimba toad females may not have more control over

267 genetic sires than females of species with external fertilisation.

268 In reptiles, high levels of polyandry may mainly arise from the combination of high male

269 benefits and low female cost from frequent mating (e.g.reviewed in Uller and Olsson, 2008).

270 Similarly, for several anurans, male harassment coupled with a male-biased OSR was found

271 to be the main driver for polyandry (Byrne and Roberts, 1999; Hase and Shimada, 2014;

272 Sztatecsny et al., 2006; Zhao et al., 2016). During the breeding season, female Nimba toads 
are most commonly found hiding in small shelters (Sandberger-Loua, personal observation),

274 probably avoiding undesired matings and harassment by males. Additionally, possibly

275 providing females the opportunity to observe males and judge on their, or their cavity's,

276 quality. Males target both single females as well as amplected pairs for mating attempts,

277 trying to dislodge the male in the latter case (Online Resource 3). Due to the viviparous

278 reproductive mode, clutch sizes are very small and a female's value hence, presumably very

279 high. This may justify the high male effort to defend territories and harass females and the

280 taken increased predation risk due to the calling and fighting activity. Mainly cavities and to a

281 lesser extend females are defended by males, possibly indicating a high value of dormancy

282 cavities for females and multiple paternity may arise if females change dormancy sites.

283 Interestingly, females also appear to physically resist mating with specific males by

284 dislodging them from their back (Online Resource 4). In externally fertilising anurans with

285 male harassment, polyandry levels similar to Nimba toads were observed (19-30\%: Lodé et

286 al., 2005; Sztatecsny et al., 2006). The level of male harassment is likely related to the OSR,

287 which becomes male-biased towards the end of the mating season. We however lack the

288 information to test the hypothesis that the documented cases of multiple paternity stem from

289 matings at the end of the reproductive period. Future studies should examine the effect of a

290 male-biased OSR, female efficiency of dislodging males and the existence of mate order

291 effects on the proportions of multiply sired clutches. Due to the internal fertilisation,

292 successfully dislodging males may give Nimba toad females more control over genetic sires

293 than females of species with external fertilisation.

295 Conclusion:

296 Representing the first study of polyandry in an anuran with internal fertilisation, we reported

297 moderate proportions of multiple paternity in the viviparous Nimba toad. High levels of 
sperm competition and cryptic female choice are unlikely for example due to the lack of morphological adaptations, and male territoriality in combination with matings which are costly for females. This suggests that pre-mating female choice is likely more important than cryptic female choice to determine the observed genetic mating system in Nimba toads.

302 Taken together, we assume that the observed frequency of multiple paternity is caused by a

303 combination of female choice and male harassment. Because such effects can also be observed in anurans with external fertilisation, they are not indicative for an increased female control over paternity in Nimba toads compared to other anurans. Nevertheless, the ability for Nimba toad females to physically resist male mating attempts in combination with internal fertilisation may give females more control over the genetic mating system compared to the majority of externally fertilising anurans.

Compliance with Ethical Standards

311 The study was funded by the Société des Mines de Fer de Guinée (SMFG), but the company

312 had no influence on study design, data collection, data analyses and interpretation, writing of

313 the manuscript and in the decision to submit the paper for publication, thus the authors

314 declare that they have no conflict of interests.

315 All applicable international, national, and/or institutional guidelines for the care and use of

316 animals were followed. All work complies with the guidelines for the use of live amphibians

317 and reptiles in research compiled by the American Society of Ichthyologists and

318 Herpetologists (ASIH), The Herpetologists' League (HL) and the Society for the Study of

319 Amphibians and Reptiles (SSAR), as well as to the IUCN policy statement on research

320 involving species at risk of extinction. The Ministère de l'Enseignement Superieur et de la

321 Recherche Scientifique (MESRS) and the Direction Nationale de la Recherche Scientifique et

322 Technique (DNRST) granted research permits ( ${ }^{\circ} 085 / \mathrm{DNPN} / 2007, \mathrm{~N}^{\circ}$ 103/DNRSIT/DN, 
$\mathrm{N}^{\circ} 020 / \mathrm{MESRS} / \mathrm{DNRSIT/2014).} \mathrm{The} \mathrm{authorities} \mathrm{from} \mathrm{the} \mathrm{Ministère} \mathrm{de} \mathrm{l'Environement} \mathrm{et} \mathrm{du}$

326 Development durable, Conakry and the Bundesamt für Naturschutz, Bonn granted CITES export $\left(\mathrm{N}^{\circ} 00314, \mathrm{~N}^{\circ} 00492\right)$ and import permits (E-3117; E-4074), respectively.

Acknowledgements

We thank the Société de Mines de Fer, Guinée (SMFG) for financial and logistic support. For support in the field we thank M. Hirschfeld, J. Doumbia, K. Camara, F. Gbêmou, B. Pivi and B. Doré. For helpful discussions we thank Linus Günther and Simon Ripperger. We thank three anonymous reviewers for their comments.

\section{Online Resources:}

336 Online Resource 1: Video1.avi, defending cavity entrance: shows a behavioural observation of a male defending a cavity entrance against another male.

Online Resource 2: Video2.avi, antagonistic behaviours: shows behavioural observations of male antagonistic behaviours as aggressive calling and fighting.

340 Online Resource 3: Video3.avi: male harassment: shows a male harassing a female, as well as

341 a male trying to dislodge an amplected male.

342 Online Resource 4: Video4.avi: female dislodges male: gives an example of a female 343 dislodging an amplected male from her back.

\section{References}

346 Adams, E.M., Jones, A.G., and Arnold, S.J. (2005). Multiple paternity in a natural population 
347 of a salamander with long-term sperm storage. Mol. Ecol. 14, 1803-1810.

348 Angel, F., and Lamotte, M. (1947). Notes sur la biologie d'un crapaud vivipare

349 Nectophrynoides occidentalis Ang. C. R. Hebd. Seances Acad. Sci. 224, 413-415.

350 Arnqvist, G. (1989). Multiple mating in a water strider: mutual benefits or intersexual

351 conflict? Anim. Behav. 38, 749-756.

352 Arnqvist, G., and Kirkpatrick, M. (2005). The evolution of infidelity in socially monogamous 353 passerines: the strength of direct and indirect selection on extrapair copulation behavior in 354 females. Am. Nat. 165 Suppl, S26-S37.

355 Ashby, B., and Gupta, S. (2013). Sexually transmitted infections in polygamous mating 356 systems. Philos. Trans. R. Soc. London, B Biol. Sci. 368, 20120048.

357 Birkhead, T.R. (1998). Cryptic female choice : Criteria for establishing female sperm choice. 358 Evolution1 52, 1212-1218.

359 Blackburn, D.G. (1999). Viviparity and Oviparity: Evolution and Reproductive Straegies.

360 Encycl. Reprod. 4, 994-1003.

361 Bouwman, K.M., Burke, T., and Komdeur, J. (2006). How female reed buntings benefit from

362 extra-pair mating behaviour: Testing hypotheses through patterns of paternity in sequential 363 broods. Mol. Ecol. 15, 2589-2600.

364 Brown, J.L., Morales, V., and Summers, K. (2010). A key ecological trait drove the evolution 365 of biparental care and monogamy in an amphibian. Am. Nat. 175, 436-446.

366 Buckley, D. (2012). Evolution of viviparity in salamanders (Amphibia, Caudata). In eLS, 367 (eLS), pp. 1-13.

368 Byrne, P.G., and Roberts, J.D. (1999). Simultaneous mating with multiple males reduces 369 fertilization success in the myobatrachid frog Crinia georgiana. Proc. R. Soc. London, B 
371 Byrne, P.G., and Roberts, J.D. (2012). Evolutionary causes and consequences of sequential 372 polyandry in anuran amphibians. Biol. Rev. 87, 209-228.

373 Byrne, P.G., and Whiting, M.J. (2011). Effects of simultaneous polyandry on offspring 374 fitness in an African tree frog. Behav. Ecol. 22, 385-391.

375 Caspers, B.A., Krause, E.T., Hendrix, R., Kopp, M., Rupp, O., Rosentreter, K., and 376 Steinfartz, S. (2014). The more the better - polyandry and genetic similarity are positively 377 linked to reproductive success in a natural population of terrestrial salamanders (Salmandra 378 salamandra). Mol. Ecol. 23, 239-250.

379 Castanet, J., Pinto, S., Loth, M.-M., and Lamotte, M. (2000). Âge individuel, longévité et 380 dynamique de croissance osseuse chez un amphibien vivipare, Nectophrynoides occidentalis 381 (Anuoure, Bufonidé). Ann. Des Sci. Nat. Zool. 24, 11-17.

382 Chen, Y.H., Cheng, W.C., Yu, H.T., and Kam, Y.C. (2011). Genetic relationship between 383 offspring and guardian adults of a rhacophorid frog and its care effort in response to paternal 384 share. Behav. Ecol. Sociobiol. 65, 2329-2339.

385 Duellman, W.E., and Trueb, L. (1986). Biology of amphibians (Baltimore: The Johns 386 Hopkins University Press).

387 Dziminski, M.A., Roberts, J.D., Beveridge, M., and Simmons, L.W. (2010). Among388 population covariation between sperm competition and ejaculate expenditure in frogs. Behav. 389 Ecol. 21, 322-328.

390 Frost, D.R. (2015). Amphibian Species of the World: an Online Reference. Version 6.0.

391 Gavaud, J. (1976). La gemétogenèse du mâle de Nectophrynoides occidentalis Angel

392 (Amphibien Anoure vivipare). I. - Étude quantitative au cours du cycle annual chez l'adulte. 
394 Grafe, T.U., Stewart, M.M., Lampert, K.P., and Rödel, M.-O. (2011). Putting toe clipping 395 into perspective: a viable method for marking anurans. J. Herpetol. 45, 28-35.

396 Gray, E.M. (1997). Female red-winged blackbirds accrue material benefits from copulating 397 with extra-pair males. Anim. Behav. 53, 625-639.

398 Haddad, C.F.B., and Prado, C.P.A. (2005). Reproductive modes in frogs and their unexpected 399 diversity in the Atlantic Forest of Brazil. Bioscience 55, 207-217.

400 Hase, K., and Shimada, M. (2014). Female polyandry and size-assortative mating in isolated 401 local populations of the Japanese common toad Bufo japonicus. Biol. J. Linn. Soc. 113, 236402242.

403 Hillers, A., Loua, N.S., and Rödel, M.-O. (2008). Assessment of the distribution and 404 conservation status of the viviparous toad Nimbaphrynoides occidentalis on Monts Nimba, 405 Guinea. Endanger. Species Res. 5, 13-19.

406 Hudson, C.M., and Fu, J. (2013). Male-biased sexual size dimorphism, resource defense 407 polygyny, and multiple paternity in the Emei moustache toad (Leptobrachium boringii). $408 \quad$ PLoS One 8.

409 Iskandar, D.T., Evans, B.J., and Mcguire, J.A. (2014). A novel reproductive mode in frogs: A 410 new species of fanged frog with internal fertilization and birth of tadpoles. PLoS One 9, 411 e115884.

412 Jehle, R., Sztatecsny, M., Wolf, J.B.W., Whitlock, A., Hödel, W., and Burke, T. (2007).

413 Genetic dissimilarity predicts paternity in the smooth newt (Lissotriton vulgaris). Biol. Lett. $414 \quad 3,526-528$.

415 Johnson, S.L., and Brockmann, H.J. (2013). Parental effects on early development: Testing 
416 for indirect benefits of polyandry. Behav. Ecol. 24, 1218-1228.

417 Jones, A.G. (2005). GERUD 2.0: A computer program for the reconstruction of parental

418 genotypes from half-sib progeny arrays with known or unknown parents. Mol. Ecol. Notes 5, $419708-711$.

420 Jones, O.R., and Wang, J. (2010). COLONY: A program for parentage and sibship inference 421 from multilocus genotype data. Mol. Ecol. Resour. 10, 551-555.

422 Knopp, T., and Merilä, J. (2009). Multiple paternity in the moor frog, Rana arvalis.

423 Amphibia-Reptilia 30, 515-521.

424 Kupfer, A., Wilkinson, M., Gower, D.J., Müller, H., and Jehle, R. (2008). Care and parentage 425 in a skin-feeding caecilian amphibian. J. Exp. Zool. 309A, 460-467.

426 Kusano, T., Toda, M., and Fukuyama, K. (1991). Testes size and breeding systems in 427 Japanese anurans with special reference to large testes in the treefrog, Rhacophorus arboreus 428 (Amphibia : Rhacophoridae). Behav. Ecol. Sociobiol. 29, 27-31.

429 Lamotte, M. (1959). Observations écologiques sur les populations naturelles de 430 Nectophrynoides occidentalis (Fam. Bufonidés). Bull. Biol. 4, 355-413.

431 Lamotte, M., and Xavier, F. (1972). Les amphibiens anoures a développement direct 432 d'Afrique. Observations sur la Biologie de Nectophrynoides tornieri (Roux). Bull. La Société 433 Zool. Fr. 97, 413-428.

434 Lamotte, M., Rey, P., and Vogeli, M. (1964). Recherches sur l'ovaire de Nectophrynoides 435 occidentalis. Batracien anoure vivipare. Arch. Anat. Microsc. Morphol. Exp. 53, 179-224.

436 Larivière, S., and Ferguson, S.H. (2003). Evolution of induced ovulation in North American 437 carnivores. J. Mammal. 84, 937-947.

438 Lodé, T., and Lesbarrères, D. (2004). Multiple paternity in Rana dalmatina, a monogamous 
territorial breeding anuran. Naturwissenschaften 91, 44-47.

440 Lodé, T., Holveck, M.J., and Lesbarrères, D. (2005). Asynchronous arrival pattern,

441 operational sex ratio and occurrence of multiple paternities in a territorial breeding anuran,

442 Rana dalmatina. Biol. J. Linn. Soc. 86, 191-200.

443 Nichols, H.J., Cant, M.A., and Sanderson, J.L. (2015). Adjustment of costly extra-group

444 paternity according to inbreeding risk in a cooperative mammal. Behav. Ecol. 26, 1486-1494.

445 Orr, T.J., and Brennan, P.L.R. (2015). Sperm storage: Distinguishing selective processes and 446 evaluating criteria. Trends Ecol. Evol. 30, 261-272.

447 Parker, G.A., and Birkhead, T.R. (2013). Polyandry: the history of a revolution. Philos.

448 Trans. R. Soc. London, Ser. B Biol. Sci. 368, 20120335.

449 Pizzari, T., and Wedell, N. (2013). The polyandry revolution. Philos. Trans. R. Soc. London, $450 \quad$ Ser. B Biol. Sci. 368, 20120041.

451 Plough, L. V, Moran, A., and Marko, P. (2014). Density drives polyandry and relatedness 452 influences paternal success in the Pacific gooseneck barnacle, Pollicipes elegans. BMC Evol. 453 Biol. 14, 81.

454 Rovelli, V., Randi, E., Davoli, F., Macale, D., Bologna, M.A., Vignoli, L., Tre, R., Marconi, 455 V., and Scienze, D. (2015). She gets many and she chooses the best: polygynandry in 456 Salamandrina perspicillata (Amphibia: Salamandridae). Biol. J. Linn. Soc. 116, 671-683.

457 Rozen, S., and Skaletsky, H.J. (2000). Primer3 on the WWW for general users and for 458 biologist programmers. In Bioinformatics Methods and Protocols: Methods in Molecular 459 Biology, S. Krawetz, and S. Misener, eds. (Humana Press, Totowa, NJ), pp. 365-386.

460 Sandberger-Loua, L., Doumbia, J., and Rödel, M.-O. (2016). Conserving the unique to save 461 the diverse - identifying key environmental determinants for the persistance of the viviparous 
462 Nimba toad in a West African World Heritage Site. Biol. Conserv. 198, 15-21.

463 Shine, R. (1987). The evolution of viviparity: Ecological correlates of reproductive mode 464 within a genus of Australian snakes (Pseudechis: Elapidae). Coppeia 3, 551-563.

465 Simmons, L.W. (2005). The evolution of Polyandry: Sperm competition, sperm selection and 466 offspring viability. Annu. Rev. Ecol. Evol. Syst. 36, 125-146.

467 Starr, C. (1984). Sperm competition, kinship, and sociality in aculeate Hymenoptera. In 468 Sperm Competition and the Evolution of Animal Mating Systems, R. Smith, ed. (Academic 469 Press, New York), pp. 428-459.

470 Sztatecsny, M., Jehle, R., Burke, T., and Hödl, W. (2006). Female polyandry under male 471 harassment: The case of the common toad (Bufo bufo). J. Zool. 270, 517-522.

472 Uller, T., and Olsson, M. (2008). Multiple paternity in reptiles: Patterns and processes. Mol. 473 Ecol. 17, 2566-2580.

474 Vieites, D.R., Nieto-Román, S., Barluenga, M., Palanca, A., Vences, M., and Meyer, A. 475 (2004). Post-mating clutch piracy in an amphibian. Nature 431, 305-308.

476 Vilter, V., and Lugand, A. (1959). Trophisme intra-utérin et croissance embryonnaire chez le 477 Nectophrynoides occidentalis Ang., crapaud totalement vivipare du Mont Nimba (Haute478 Guinée). Comptes Rendues Des Sceances La Sociéte Biol. Paris 153, 29-32.

479 Wake, M.H. (1978). The reproductive biology of Eleutherodactylus jasperi (Amphibia, 480 Anura, Leptodactylidae), with comments on the evolution of live-bearing systems. J. 481 Herpetol. 12, 121-133.

482 Wake, M.H. (1993). Evolution of oviductal gestation in amphibians. J. Exp. Zool. 266, 394483413.

484 Wake, M.H. (2015a). Fetal adaptations for viviparity in amphibians. J. Morphol. 276, 941- 
486 Wake, M.H. (2015b). How do homoplasies arise? Origin and maintenance of reproductive 487 modes in amphibians. In Great Transformations in Vertebrate Evolution, K.P. Dial, N. 488 Shubin, and E.L. Brainerd, eds. (The University of Chicago Press),

489 Wells, K.D. (2010). The ecology and behavior of amphibians (The University of Chicago 490 Press).

491 Wood, S.N. (2011). Fast stable restricted maximum likelihood and marginal likelihood 492 estimation of semiparametric generalized linear models. J. R. Stat. Soc. Ser. B 73, 3-36.

493 Wourms, J.P., and Lombardi, J. (1992). Reflections on the evolution of piscine viviparity. 494 Integr. Comp. Biol. 32, 276-293.

495 Xavier, F. (1971). Recherches sur l'endocrinologie sexuelle de la femelle de Nectophrynoides 496 occidentalis Angel (Amphibien anour vivipare). Faculté des sciences Paris, Thèse de doctorat 497 d'état ès-Sciences Naturelles.

498 Xavier, F. (1974). La pseudogestation chez Nectophrynoides occidentalis Angel. Gen. Comp. 499 Endocrinol. 22, 98-115.

500 Xavier, F. (1977). An exceptional reproductive strategy in anura: Nectophrynoides

501 occidentalis Angel (Bufonidae), an example of adaptation to terrestrial life by viviparity. In

502 Major Patterns in Vertebrate Evolution, M.K. Hecht, P.C. Goody, and B.M. Hecht, eds.

503 (NATO advanced Study Institude, Series A, Life Sciences), pp. 545-552.

504 Xavier, F. (1986). La reproduction des Nectophrynoides. In Traité de Zoologie - Anatomie, 505 Sysématique, Biologie - Batraciens, P.-P. Grassé, and M. Delsol, eds. (Paris, New York, 506 Barcelone, Milan, Mexico, Sao Paulo: Masson), pp. 497-513.

507 Xavier, F., Zuber-Vogeli, M., and Le Quang Trong, Y. (1970). Recherches sur l'activité 
508 endocrine de l'ovaire de Nectophrynoides occidentalis Angel (Amphibien Anoure vivipare) -

509 I. Etude histochimique. Gen. Comp. Endocrinol. 15, 425-431.

510 Zhao, M., Li, C., Zhang, W., Wang, H., Luo, Z., Gu, Q., Gu, Z., Liao, C., and Wu, H. (2016).

511 Male pursuit of higher reproductive success drives female polyandry in the Omei treefrog.

512 Anim. Behav. 111, 101-110.

513 
514 Figure caption

515 Fig 1 Operational sex ratio for Nimba toads within the rainy season. Shown is the average

516 operation sex ratio (OSR) per calendar week, based on annual monitoring data in those areas

517 where females for this study were captured; data recorded between 2007 and 2014 (based on

518333 squares $(5 \times 5 \mathrm{~m})$ examined for Nimba toads). The mating season is indicated in grey. The

519 line shows the predictions of the OSR of an additive generalised model. The horizontal line

520 indicates and equal OSR. The inset figure in the upper left shows a brightly coloured male,

521 the inset in the lower right a pair in amplexus. The graphic was produced in $\mathrm{R}$, the inset

522 photographs added in Illustrator. 